Provided for non-commercial research and education use. Not for reproduction, distribution or commercial use.

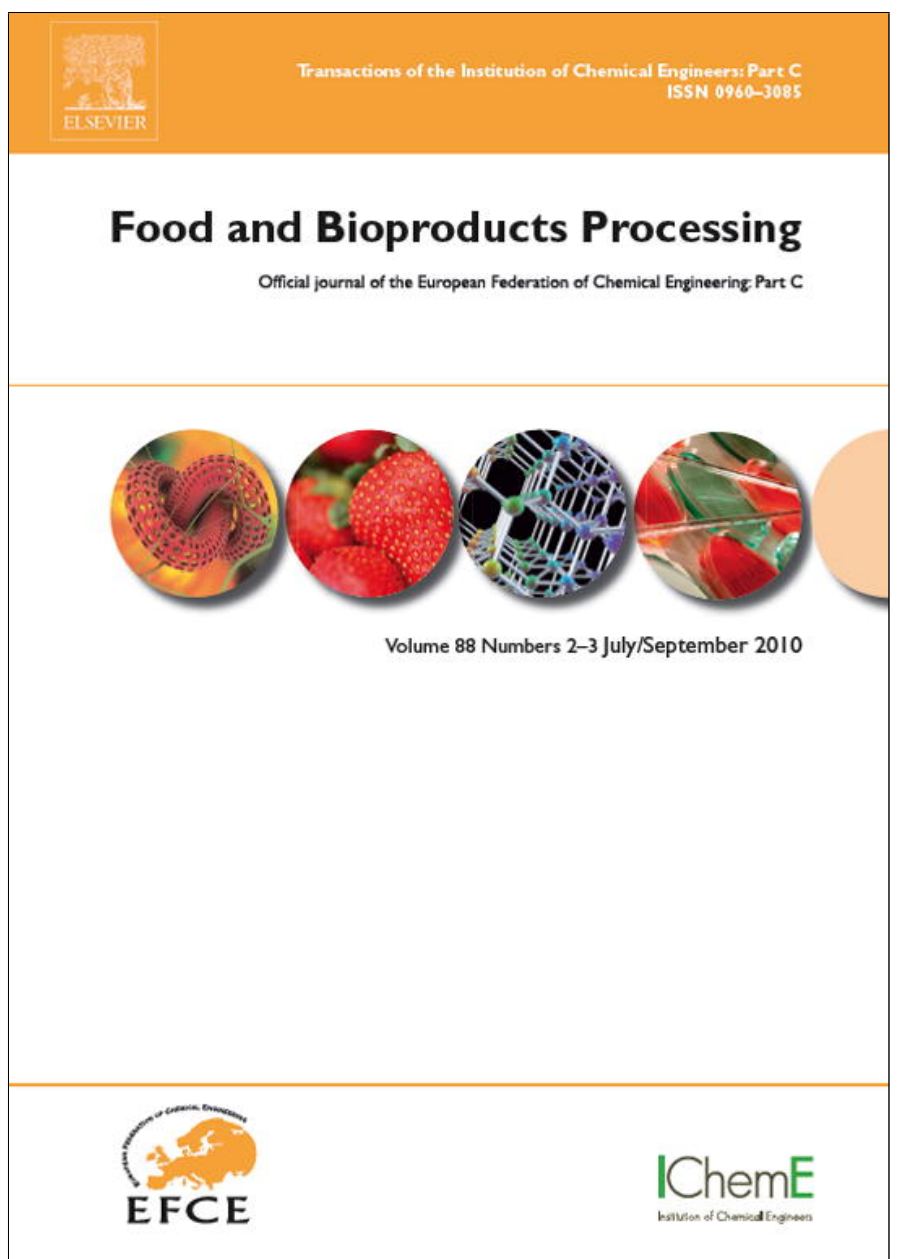

This article appeared in a journal published by Elsevier. The attached copy is furnished to the author for internal non-commercial research and education use, including for instruction at the authors institution and sharing with colleagues.

Other uses, including reproduction and distribution, or selling or licensing copies, or posting to personal, institutional or third party websites are prohibited.

In most cases authors are permitted to post their version of the article (e.g. in Word or Tex form) to their personal website or institutional repository. Authors requiring further information regarding Elsevier's archiving and manuscript policies are encouraged to visit:

http://www.elsevier.com/copyright 


\title{
Modelling extrudate expansion in a twin-screw food extrusion cooking process through dimensional analysis methodology
}

\author{
Hongyuan Cheng, Alan Friis* \\ Food Production Engineering, National Food Institute, Technical University of Denmark, Søltofts Plads, \\ Building 227, DK-2800, Lyngby, Denmark
}

\begin{abstract}
A B S T R A C T
A new phenomenological model is proposed to correlate extrudate expansion and extruder operation parameters in a twin-screw food extrusion cooking process. Buckingham's pi dimensional analysis method is applied to establish the model. Three dimensionless groups, i.e. pump efficiency, water content and temperature, are formed to model the extrusion process from dimensional analysis. The model is evaluated with experimental data for extrusion of whole wheat flour and fish feed. The average deviations of the model correlations are $5.9 \%$ and $9 \%$ based on experimental data for the whole wheat flour and fish feed extrusion, respectively. An alternative four-coefficient extrudate expansion equation is also suggested for the three dimensionless groups. The average deviations of the alternative equation are respectively $5.8 \%$ and $2.5 \%$ in correlation with the same set of experimental data.
\end{abstract}

(c) 2010 The Institution of Chemical Engineers. Published by Elsevier B.V. All rights reserved.

Keywords: Extrusion; Extrudate expansion; Model; Twin-screw extruder; Dimensional equation

\section{Introduction}

Extrusion cooking is a highly versatile food manufacturing method by offering continuous and flexible processing which allows producing food with diverse textures and shapes. Extrusion cooking is carried out with an extruder in which a food material is conveyed and subjected to heat, mechanical work and compression, then forced through a discharge die. In the extruder, mixing, cooking, shear, cooling and shaping take place. For decades, tremendous research and development efforts for extrusion equipment and process have been made according to new market trends, consumer's demands and raw material changes. Today, a large variety of snack foods, flat breads, breakfast cereals, pet food and animal feeds are manufactured by the extrusion cooking method.

Although the research work for the extrusion cooking has been carried out for many years, the understanding of the material changes within extrusion and the effects of process parameters on product qualities are still very limited (Bruin et al., 1978; Bruin and Jongen, 2003; Kokini et al., 1992b). Trial and error methods often dominate product development and process scale-up for extrusion cooking processes. The process applications are often confined to very specific studied cases and are difficult to extend to new recipes extrusion cooking. While much of the food industry is trying to make an exact science of production (with success in many segments), extrusion is one segment that still relies heavily on principles of art (Moraru and Kokini, 2003).

In a food extrusion cooking process, the product expansion, i.e. extrudate expansion, is a fundamentally important property describing the product quality and directly related to degree of cook. Unless the extrudate expansion meets some specifications, the product is not acceptable. Thus, the understanding of the effects of process parameters on extrudate expansion becomes crucial for the extrusion cooking process. Many theories and models have been proposed to describe the extrudate expansion (Alvarez-Martinez et al., 1988; Bruin and Jongen, 2003; Tayeb et al., 1992; Moraru and Kokini, 2003). Some researchers use empirical regressions through process operation parameters and raw material compositions to explain the extrudate expansion (Cai and Diosady, 1993; Ding et al., 2006; Altan et al., 2008). These empirical regressions are

\footnotetext{
* Corresponding author.

E-mail addresses: Chenghongyuan@gmail.com (H. Cheng), alfr@food.dtu.dk (A. Friis).

Received 20 March 2009; Received in revised form 25 August 2009; Accepted 1 January 2010

0960-3085/\$ - see front matter @ 2010 The Institution of Chemical Engineers. Published by Elsevier B.V. All rights reserved. doi:10.1016/j.fbp.2010.01.001
} 
often constructed with linear and quadratic process parameter terms according to the statistical significance of these terms, such as the commonly used response surface method. Kokini et al. (1992a) proposed a five-step mechanism for extrusion cooking process to represent the expansion. Brümmer et al. (2002) suggest a correlation for the expansion and functional properties of corn starch extrudate based on the average molecular weight of the material molecules. These theoretic and empirical models can often represent the specific extrusion process studied, but may not be extended to another extrusion case. Thus, process engineers cannot directly apply those models to analyse their interested extrusion cooking processes.

There is a move for consuming high fiber foods to get health benefit. The inclusion of high levels of fiber and other additives in breakfast cereals will decrease product expansion and result in a harder, less acceptable product. In order to make more efficient development of new products, food engineers need a quantitative guide other than principle of art in the product development. A quantitative model for the extrusion cooking process will be very effective for the engineers to speed up the product development and reduce raw materials cost.

In this work, a new phenomenological modelling framework is proposed to correlate the extrudate expansion and extrusion process parameters through dimensional analysis methodology. As dimensional analysis is independent of system or equipment structure, the proposed equation may provide a general expression for the extrudate expansion behaviours and process operation conditions. This work includes extrusion cooking trials, model development and data analysis.

\section{Extrusion cooking experiments}

\subsection{Extruder and extrusion cooking}

A Werner \& Pflederer Continua 37 co-rotating twin-screw extruder was used. The barrel of the extruder consists of five zones with independent heating and cooling capabilities. The temperature of the first zone (starting from the feed point) was held at room temperature. The temperature of the zone 5 (closest zone to die) was varied according to an experimental plan (will be discussed below). The zone temperatures are extruder barrel temperatures. The raw material was introduced into the extruder by a volumetric twin-screw feeder in the first barrel segment. A dosing pump was used to add water and liquid additives to the feed solids at the first and third zone, respectively. The extruder was equipped with two circular dies having a diameter of $3 \mathrm{~mm}$. The recorded data for the extrusion process are zone 1-5 temperatures, heating oil temperatures in different zones, feed flowrate, added water flowrate, added liquid additive flowrate, screw speed, die pressure, moment, die temperature and blade speed. The moment can be converted to a torque value with an equation provided by the extruder producer.

The independent extrusion variables were varied in the following ranges: barrel temperature, $101-149^{\circ} \mathrm{C}$; feed water content, 9.2-15.8\%; screw speed, 208-393 rpm. In dimensional analysis principle, the experiments must cover the full adjustable range of the values of the relevant variables. However, the practical ranges of the barrel temperature, screw speed and feed water content were suggested by extrusion process engineers according to the extruder capabilities. The extrudates were cut by a three-blade adjustable knife assembly rotating at $335 \mathrm{rpm}$ and conveyed to a horizontal belt dryer. The extrudates were dried at $100^{\circ} \mathrm{C}$ for $12 \mathrm{~min}$ to final moisture content of $5-8 \%$. The samples were subsequently sealed in plastic bags and stored at $4{ }^{\circ} \mathrm{C}$. The extruder settings were allowed to achieve and maintain a steady state condition for approximately $15 \mathrm{~min}$ prior to sample collection.

The bulk density of dried extruded pellets was determined by filling a $1 \mathrm{l}$ cup. The pellets were tapped in order to pack it together. The weight was recorded and the bulk density was calculated according to the weight of 11 extrudates. The bulk density results were the average of three readings. The lab room temperature was recorded in case of the need to correct the volume of the metal cup. The moisture content of the extrudates was determined in three replicates by drying approximately $1.5 \mathrm{~g}$ of each sample in an infrared dryer at $160^{\circ} \mathrm{C}$ until constant weight.

Two sorts of raw material recipes were used in the extrusion trials. One is whole wheat flour, edible oil and water for producing whole wheat flour product. The other is whole wheat flour, pea flour and meat protein for producing fish feed. A total of 16 runs were carried out for whole wheat flour extrusion and 70 runs for fish feed extrusion.

\subsection{Experimental design}

An experimental design for the extrusion trials was determined within the limitation of the extruder mentioned above. A Central Composite Design (CCD) (Esbensen et al., 2000) was used in the study, which was based on five levels of three variables. The independent extrusion variables were barrel temperature in zone 5, feed water content and screw speed. All other parameters were kept constant. Operating ranges and five standardized levels were established by preliminary study of each variable. The CCD result is given in Table 1. In Table 1, $\mathrm{T}_{5}\left({ }^{\circ} \mathrm{C}\right)$ is the temperature of zone 5 (closest zone to die), $X_{\mathrm{W}}$ is the water content (weight percent, \%), $N_{\mathrm{s}}$ is the screw speed (rpm), $\alpha$ equals to 1.682 (given by the design). Here $\alpha$ is the distance of the axial runs from the design centre (Montgomery, 2001).

The experimental plan comprises 15 trials (8 cube points, 6 star points and 1 central point) for the whole wheat flour extrusion. The fish feed extrusion was carried out for eight different recipes. In the experimental design, the extrudate expansion was set as the objective of the extrusion process operation for the whole wheat flour and fish feed products. In this work, only the response surface method was used to perform the experiment. The developed model in this work was not applied to design the trials.

\subsection{Extrusion experiments}

The whole wheat flour was processed in the Werner \& Pfleiderer twin-screw extruder following Table 1, yielding 15 experimental runs. First, the 15 trials were made to search the optimal extrusion conditions for maximum expansion. Subsequently one more run was made to obtain the maximum expansion. The conditions for the last trial were estimated through analysing the data using the response surface methodology to predict the optimal conditions. The total trial capacity (dry flour flow + water flow) was between $22 \mathrm{~kg} / \mathrm{h}$ and $27 \mathrm{~kg} / \mathrm{h}$, where the dry flour flowrate was kept about constant, the water flowrate was changed with the need of water 
Table 1 - Coded levels for the central composite design.

\begin{tabular}{lccccc} 
Variables & \multicolumn{5}{c}{ Levels } \\
\cline { 2 - 6 } & $-\alpha$ & -1 & 0 & 1 & $+\alpha$ \\
\hline$T_{5}\left({ }^{\circ} \mathrm{C}\right)$ & 101 & 111 & 125 & 139 & 149 \\
$\mathrm{X}_{\mathrm{w}}(\%)$ & 9.2 & 10.5 & 12.5 & 14.5 & 15.8 \\
$\mathrm{~N}_{\mathrm{s}}(\mathrm{rpm})$ & 208 & 245 & 300 & 355 & 393 \\
\hline
\end{tabular}

content for the system. In the experimental work, the wheat flour, water and additives were directly added into extruder without pre-mixing. Totally, 70 sets of data were obtained for the fish feed extrusion with eight different recipes.

\section{Modelling of extrudate expansion}

\subsection{Extrudate expansion model}

The extrudate expansion is defined as the weight of extrudates per unit volume, which is so called bulk density. The definition for individual extrudate expansion is proposed by AlvarezMartinez et al. (1988), which includes sectional expansion, longitudinal expansion and volumetric expansion indices. In this work, we used the bulk density to represent extrudate expansion.

In a food extrusion cooking process, the extrudate expansion reflects the interaction between extrusion equipment design, process operation variables and processing raw material properties. The equipment design may include pre-mixing method, various screw structures, die shape design, etc. The process operation variables are the adjustable process control parameters. A suitable combination of the screw structures, die shape design and raw material composition is also crucial for extrudate expansion. In this work, we will only study the relationship among extrudate expansion, operation parameters and main composition changes in processing raw materials. The mechanical structures of extrusion process were treated as fixed factors.

The extrudate expansion is related to many process parameters in an extrusion cooking process, e.g. different zone temperatures, die temperature and pressure, process capacity, screw speed, torque, water content, fluid viscosity, specific mechanical energy, etc. Different raw material components also affect the extrudate expansion. Starch, proteins, fat and fiber have different roles to interact with other ingredients to establish product characteristics under various extrusion conditions. Because the compositional and structural complexities of the raw material as well as the large number of operational parameters involved in the extrusion process, obtaining the desired extrudate properties, e.g. optimal expansion and texture, is a challenge task.

\subsection{Modelling method}

As discussed in Section 1, many theories and methods have been developed to correlate the extrudate expansion and process parameters. However, these models are often limited in their studied specific cases. The developed models cannot represent the extrudate expansion for a new recipe production in the same production line and can be rarely used for another extrusion production line. The expressions of these models often have to be modified for a new recipe production in the same extrusion line. For an engineering purpose, a general model is very necessary to explain the extrudate expansion behaviours. The general model should have a fixed expression format for different recipes in the same production process and also independent of extrusion equipment structures.

Dimensional analysis method is a fundamental method to reduce complex physical problems to the simplest forms for an engineering process. The dimensional analysis theory includes Rayleigh method (Rayleigh, 1915) and Buckingham pi method (Buckingham, 1914). The theorem states that if we have a physically meaningful equation involving a certain number of physical variables and these variables are expressible in terms of independent fundamental physical quantities, then the original expression is equivalent to an equation involving a set of dimensionless variables constructed from the original variables. As a fundamental principle in engineering and science, the dimensional analysis method has been adapted in many applications, such as chemistry and physics (Weast and Astle, 1981), chemical engineering (Perry and Green, 1999), food engineering (Lim et al., 2007), biology (Stahl, 1962), mechanics (Barenblatt, 2003). Many difficult subjects can be described from dimensional analysis method even the physical mechanism of a system is completely not clear for researchers. In experiments, those empirical results are sometimes or often difficult to present in a readable way such as in the form of graphs. Thus, dimensional analysis provides a method to choose the relevant data and to present them concisely. This will help the development of theoretical modelling of the problem. However, this method has not been seen to be used to describe the relationship between process parameters and product qualities in food extrusion process. In this work, we will use the Buckingham pi method to construct a dimensionless equation in correlation of the expansion of extrudate and extrusion operational parameters.

\subsection{Model formulation}

To apply the dimensional analysis theory for study of an engineering system, the first step is to identify the key variables. Next, these key variables will be used to form some dimensionless groups. Because the dimensional analysis theory itself does not give any guide for the key variable analysis, we have to search for the key variables from a basic understanding of the extrusion process. In the food extrusion process, temperature and moisture content have strong effects on extrudate expansion. Moisture content maintains the starch matrix in the rubbery state and then free-flowing state at different process temperatures, which allows bubbles to form and expansion to take place. Temperature influences the rheological properties of the starch melts and allows the formation of the superheated steam that is the driving force in expansion (Moraru and Kokini, 2003). Specific mechanical energy (SME) and residence time (relevant to screw speed) are two other important parameters and are widely used to model the extrudate expansion. Raw material compositions, particle size distribution and raw material pre-mixing conditions also affect the extrudate expansion. All these parameters 
Table 2 - Selected process parameters for dimensional analysis.

\begin{tabular}{lclc} 
Parameters & Symbols & Units & Dimensions \\
\hline Die temperature & $\mathrm{T}_{\mathrm{d}}$ & ${ }^{\circ} \mathrm{C}$ & $\mathrm{T}$ \\
Zone 1 temperature & $\mathrm{T}_{\mathrm{o}}$ & ${ }^{\circ} \mathrm{C}$ & $\mathrm{T}$ \\
Total inlet flowrate & $\mathrm{F}_{\mathrm{T}}$ & $\mathrm{kg} / \mathrm{h}$ & $\mathrm{M} / \mathrm{t}$ \\
Added water flowrate & $\mathrm{F}_{\mathrm{W}}$ & $\mathrm{kg} / \mathrm{h}$ & $\mathrm{M} / \mathrm{t}$ \\
Screw speed & $\mathrm{N}_{\mathrm{s}}$ & $1 / \mathrm{min}$ & $1 / \mathrm{t}$ \\
Torque & $\tau$ & $\mathrm{Nm}$ & $\mathrm{F} \cdot \mathrm{L}$ \\
Die pressure & $\mathrm{P}_{\mathrm{d}}$ & $\mathrm{bar}$ & $\mathrm{F} / \mathrm{L}^{2}$ \\
Bulk density & $\bar{\rho}_{\mathrm{B}}$ & $\mathrm{g} / \mathrm{l}$ & $\mathrm{M} / \mathrm{L}^{3}$ \\
\hline
\end{tabular}

were taken into account in the dimensional analysis procedure. However, these factors were divided into three important groups: raw material mixing and particle size condition, raw material component and extruder operation parameters. To simplify the model formation, we only studied the effects of process operation parameters on extrudates expansion, i.e. temperature, moisture content, SME and residence time (relevant to screw speed), and kept others constant.

Based on the above discussions, the selected key variables for the extrusion process are given in Table 2. In Table $2, T_{d}$ is the die temperature $\left({ }^{\circ} \mathrm{C}\right)$, measured just before die, $T_{0}$ is the zone 1 (feed zone) temperature $\left({ }^{\circ} \mathrm{C}\right.$ ), which was considered representative for the raw material initial temperature and given a fixed value of $25^{\circ} \mathrm{C}, \mathrm{F}_{\mathrm{T}}$ is the total flowrate of all ingredient materials (wheat flour, water and additives) for the extruder $(\mathrm{kg} / \mathrm{h}), F_{\mathrm{w}}$ is the water flowrate added into the extruder $(\mathrm{kg} / \mathrm{h})$, $N_{\mathrm{s}}$ is the screw speed (rpm), $\tau$ is the torque $(\mathrm{Nm}), P_{\mathrm{d}}$ is the die pressure (bar), $\bar{\rho}_{\mathrm{B}}$ is the bulk density of extrudates (g/l). In Table 2, the dimensions $T, M, t, F$ and $L$, respectively represent temperature, mass, time, force and length. From the key extrusion process parameters, a variable and unit matrix were formed and given in Table 3.

From Table 3 it can be seen that the rank of the matrix is five; the number of the physical variables is eight. According to Buckingham pi theorem, exactly only three dimensionless groups should be established from the matrix. From Table 3, we found the three dimensionless groups as follows:

$\frac{P_{\mathrm{d}} \cdot F_{\mathrm{T}}}{\bar{\rho}_{\mathrm{B}} \cdot \tau \cdot N_{\mathrm{S}}}, \quad \frac{F_{\mathrm{w}}}{F_{\mathrm{T}}}$ and $\frac{\mathrm{T}_{\mathrm{d}}}{\mathrm{T}_{0}}$

In the dimensionless groups, the group $F_{\mathrm{w}} / \mathrm{F}_{\mathrm{T}}$ represents the water content of the processing material (not including the nature moisture content of grain flour). The group $T_{d} / T_{0}$ is the temperature $\left({ }^{\circ} \mathrm{C}\right)$ changes of the processing material from its initial condition to the vicinity of die before flash-out from extruder. Here, the use of Celsius temperature other than Kelvin is just a first arbitrary choice with available experimental data. The group $\left(P_{d} \cdot F_{T}\right) /\left(\bar{\rho}_{\mathrm{B}} \cdot \tau \cdot N_{\mathrm{s}}\right)$ represents the extrusion pump efficiency of the extrusion process. Within the group, the term $\tau \cdot \mathrm{N}_{\mathrm{S}} / \mathrm{F}_{\mathrm{T}}$ reflects the widely used specific mechanical energy (SME). As the processed material loses its water content after discharged from die, the term $F_{\mathrm{T}} / \bar{\rho}_{\mathrm{B}}$ does not represent the real volume flow. Therefore, the extrusion pump efficiency is not exactly identical to the regular pump efficiency that is defined as:

Pump efficiency $=\frac{\text { power output }}{\text { power input }}$

where the power output is the product of the total dynamic head and the mass of fluid pumped in a given time. However, the extrusion pump efficiency is linearly proportional to the normal pump efficiency if we can assume that the dry extrudate bulk density is linearly correlated to the density of the processed material at just before flashing-out discharge die.

From the dimensionless groups, we obtained an equation by following a typical suggestion by Buckingham theorem as follows:

$$
\left(\frac{F_{\mathrm{W}}}{F_{\mathrm{T}}}\right)^{\alpha}\left(\frac{\mathrm{T}_{\mathrm{d}}}{\mathrm{T}_{0}}\right)^{\beta}\left(\frac{\mathrm{P}_{\mathrm{d}} \cdot F_{\mathrm{T}}}{\bar{\rho}_{\mathrm{B}} \cdot \tau \cdot N_{\mathrm{S}}}\right)^{\gamma}=\mathrm{K}
$$

where $\alpha, \beta, \gamma, \mathrm{K}$ are dimensionless coefficients.

Set $\gamma=1.0$ in Eq. (2), we have

$\bar{\rho}_{\mathrm{B}}=\mathrm{K}\left(\mathrm{X}_{\mathrm{W}}\right)^{\alpha}\left(\frac{\mathrm{T}_{\mathrm{d}}}{\mathrm{T}_{0}}\right)^{\beta}\left(\frac{\mathrm{P}_{\mathrm{d}} \cdot \mathrm{F}_{\mathrm{T}}}{\tau \cdot \mathrm{N}_{\mathrm{s}}}\right)$

where $X_{\mathrm{W}}$ is the water content of feed material and equals to $F_{\mathrm{w}} / F_{\mathrm{T}}$, weight fraction, $\mathrm{K}, \alpha$ and $\beta$ are experimentally determined dimensionless coefficients. Using the dimensions of the physical variables in Table 2, the dimensionless group $\left(P_{\mathrm{d}} \cdot \mathrm{F}_{\mathrm{T}}\right) /\left(\bar{\rho}_{\mathrm{B}} \cdot \tau \cdot \mathrm{N}_{\mathrm{S}}\right)$ has a conversion constant, 104/6.

Eq. (3) represents those important operational parameters in an extrusion cooking process, i.e. temperature, moisture content, energy, cooking time and capacity. Because Eq. (3) has only three system dependent coefficients, a relatively small amount of experimental data can determine these coefficients.

In the formulation of the dimensionless equation, we assumed that the raw material mixing and particle size condition and raw material component were fixed. Eq. (3) only represents the effects of operation parameters on product expansion. However, Eq. (3) is not the only expression for the three dimensionless groups. Any other type of algebraic expression among the three groups that accurately fits experimental data would be an equally valid manner of Eq. (3).

From the experimental data of whole wheat flour extrusion, the model coefficients were determined according to an objective function as:

obj $=\min \sum_{i=1}^{n}\left[\bar{\rho}_{\mathrm{B}, \mathrm{i}}^{\exp }-\bar{\rho}_{\mathrm{B}, \mathrm{i}}^{\mathrm{cal}}\right]$

where $\bar{\rho}_{\mathrm{B}}^{-\exp }$ and $\bar{\rho}_{\mathrm{B}}^{\text {cal }}$ are respectively the experimental bulk density and fitted density of Eq. (3). The obtained coefficients are given in Table 4 . The average absolute deviation (AAD) of the model correlation for the experimental bulk density data

\section{Table 3 - Selected variables and units matrix.}

\begin{tabular}{|c|c|c|c|c|c|c|c|c|}
\hline Units & $T_{0}$ & $\mathrm{~T}_{\mathrm{d}}$ & $F_{\mathrm{T}}$ & $F_{\mathrm{w}}$ & $N_{\mathrm{S}}$ & $P_{d}$ & $\tau$ & $\bar{\rho}_{\mathrm{B}}$ \\
\hline$T$ & 1 & 1 & 0 & 0 & 0 & 0 & 0 & 0 \\
\hline$M$ & 0 & 0 & 1 & 1 & 0 & 0 & 0 & 1 \\
\hline$t$ & 0 & 0 & -1 & -1 & -1 & 0 & 0 & 0 \\
\hline$F$ & 0 & 0 & 0 & 0 & 0 & 1 & 1 & 0 \\
\hline L & 0 & 0 & 0 & 0 & 0 & -2 & 1 & -3 \\
\hline
\end{tabular}


Table 4 - Regression coefficients of Eq. (3) for whole wheat flour extrusion.

\begin{tabular}{cccc} 
& K & $\alpha$ & $\beta$ \\
\hline Whole wheat flour & 13,508 & 0.7774 & -0.2882 \\
\hline
\end{tabular}

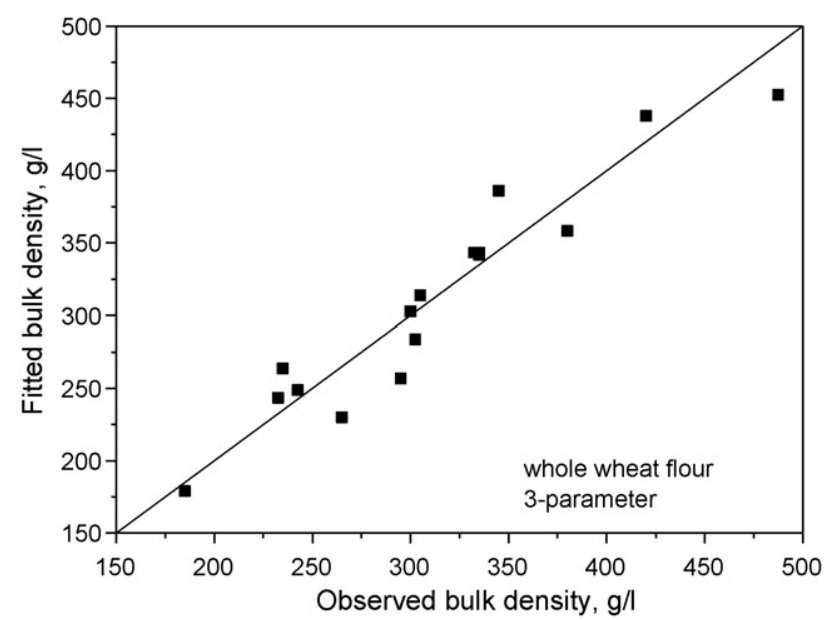

Fig. 1 - Observed and fitted value for the bulk density of whole wheat flour extrudate with Eq. (3).

is $5.9 \%$, where $\mathrm{AAD}$ is calculated as:

$\operatorname{AAD}(\%)=\frac{1}{n} \sum_{n}\left[\frac{\bar{\rho}_{\mathrm{B}}^{\exp }-\bar{\rho}_{\mathrm{B}}^{\mathrm{cal}}}{\bar{\rho}_{\mathrm{B}}^{\exp }}\right]$

In Eq. (5), $n$ is the number of experimental runs. As shown in Fig. 1, the model satisfactorily correlates the experimental data. As shown in Fig. 2, the bulk density estimation errors are evenly distributed. In Fig. 2, the relative deviation $\left(R_{d}\right)$ is calculated as:

$R_{\mathrm{d}}(\%)=\frac{\bar{\rho}_{\mathrm{B}}^{\exp }-\bar{\rho}_{\mathrm{B}}^{\mathrm{cal}}}{\rho_{\mathrm{B}}^{-\exp }}$

\subsection{Application of Eq. (3) in extrusion process data} analysis

The proposed Eq. (3) provides a concise and consistent way to quantitatively observe the interactions between process parameters and extrudate expansion, i.e. bulk density. In extrusion process experiments or operations, a large amount of data may be obtained. Response surface method or other statistic methods are often used to analyse the data and estab-

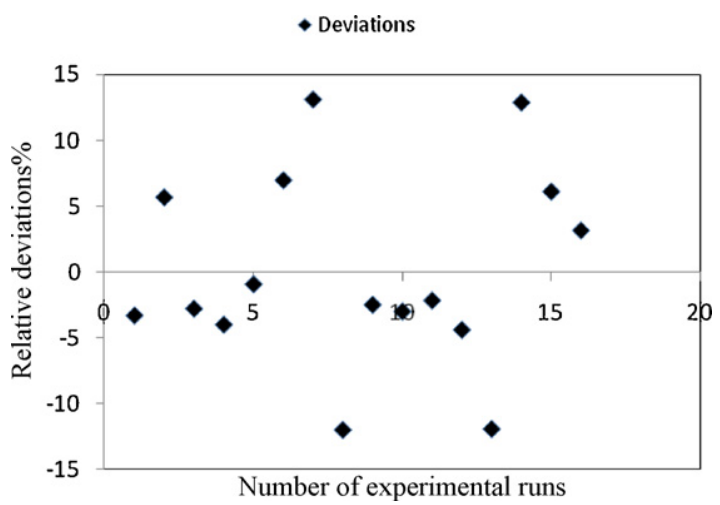

Fig. 2 - Relative deviations of Eq. (3) in correlation with bulk density and extusion operating conditions.

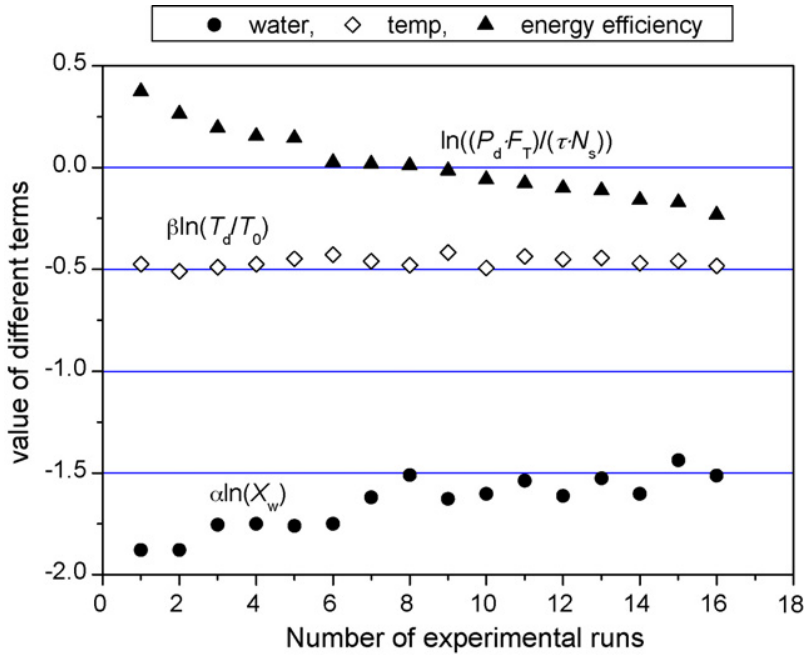

Fig. 3 - Interactions of the terms of Eq. (7).

lish process description model according to statistic methods. However, the regression model produced from the statistic methods may have different format if it is set up from different people or algorithms for the same set of data. Therefore, one may have difficulties to understand the exact interactions among the operation parameters and product expansion from these different equations. Eq. (3) provides a consistent format to correlate the operation parameters and product expansion of different ingredients extrusion in the same extruder. From the correlation results, one can clearly see the interactions of process parameters and product expansions, and search for the optimal operation region for an extrusion process.

For example, Eq. (3) can be re-organized as:

$\ln \bar{\rho}_{\mathrm{B}}=\ln K+\alpha \ln X_{\mathrm{W}}+\beta \ln \left(\frac{\mathrm{T}_{\mathrm{d}}}{\mathrm{T}_{0}}\right)+\ln \left(\frac{\mathrm{P}_{\mathrm{d}} \cdot \mathrm{F}_{\mathrm{T}}}{\tau \cdot \mathrm{N}_{\mathrm{S}}}\right)$

If we take the 16 sets of experimental data for whole wheat flour extrusion, we can plot the term $\alpha \ln \mathrm{X}_{\mathrm{W}}, \beta \ln \left(\mathrm{T}_{\mathrm{d}} / \mathrm{T}_{0}\right)$ and $\ln \left(\left(\mathrm{P}_{\mathrm{d}} \cdot \mathrm{F}_{\mathrm{T}}\right) / \tau \cdot \mathrm{N}_{\mathrm{s}}\right)$ versus the runs of the 16 sets of experimental data, as shown in Fig. 3, as $\ln K=9.511$ is a constant (given in Table 4) and will not change the value of $\ln \bar{\rho}_{\mathrm{B}}$. In Fig. 3 , "water", "temp" and "energy efficiency", respectively represent the term $\alpha \ln X_{\mathrm{w}}, \beta \ln \left(\mathrm{T}_{\mathrm{d}} / \mathrm{T}_{0}\right)$ and $\ln \left(\left(\mathrm{P}_{\mathrm{d}} \cdot \mathrm{F}_{\mathrm{T}}\right) / \tau \cdot \mathrm{N}_{\mathrm{s}}\right)$ in Eq. (7). Within the three dimensionless terms, the regular process operational (controllable) parameters are $X_{\mathrm{W}}, T_{\mathrm{d}}$ and $\mathrm{N}_{\mathrm{s}}$ for a fixed extruder configuration and constant $F_{\mathrm{T}}$. For the data set and Table 4, we know $\ln K=9.511$ and $\ln \bar{\rho}_{\mathrm{B}}=5.0-6.0$.

From Fig. 3, the effects of process operation parameter interactions on $\ln \bar{\rho}_{\mathrm{B}}$ can be easily recognized although the physical mechanism behind such interactions are not reflected from Eq. (7). From Fig. 3, it can be seen the "water" and "temp" term are all negative, the "energy efficiency" term changes from positive to negative values. The "temp" line is almost a straight line. In experiments, the variation range of the die temperature was $102.5-147.5^{\circ} \mathrm{C}$. It may be explained that the extrusion of the whole wheat flour needs a certain level of temperature; after the processing ingredients reached a temperature region, the product expansion is not sensitive with temperature. From the example it has been demonstrated that the proposed dimensionless equation gives an opportunity to correlate the experimental data in a consistent format, and opens a way to build a more comprehensive physical meaningful model for a food extrusion cooking process. 


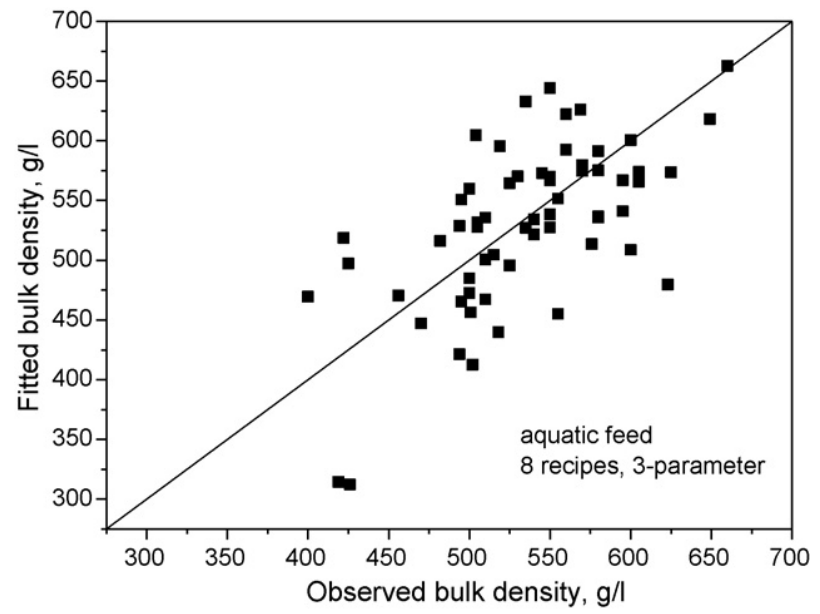

Fig. 4 - Observed and fitted value for the bulk density of fish feed extrudate with Eq. (3).

\subsection{Evaluation of the extrudate expansion model}

A set of fish feed extrusion experimental data was used to evaluate the proposed extrudate expansion model, i.e. Eq. (3). The fish feed extrusion trials were carried out in the same extrusion pilot equipment discussed in above section. Totally, eight different raw material recipes were used in the fish feed extrusion trials. Eq. (3) was applied to correlate all the product expansion data for 8 different fish feed recipes. The absolute average deviation of the correlation was $9 \%$. The correlation results show that the same equation can correlate the process parameters and product expansion data for both fish feed and whole wheat flour extrusions. The correlation results are given in Fig. 4.

\subsection{4-Parameter extrudate expansion model}

As discussed in above section, if we set $\gamma=1.0$ in Eq. (2), we obtain the 3-parameter Eq. (3). However, if we use the $\gamma$ as one extra coefficient in Eq. (2), we will have a more flexible equation for the extrudate expansion model. Thus, a modified 4-parameter equation is formed as:

$\bar{\rho}_{\mathrm{B}}=\mathrm{K}\left(\mathrm{X}_{\mathrm{W}}\right)^{\alpha}\left(\frac{\mathrm{T}_{\mathrm{d}}}{\mathrm{T}_{0}}\right)^{\beta}\left(\frac{\mathrm{P}_{\mathrm{d}} \cdot \mathrm{F}_{\mathrm{T}}}{\tau \cdot \mathrm{N}_{\mathrm{S}}}\right)^{\gamma}$

In the equation, all symbols have the same meanings as in Eq. (3). It should be noticed that the coefficient $K$ now is not a dimensionless value in Eq. (8). As one more regression coefficient is employed in Eq. (8), more experimental data are needed in regression calculation to get a set of reliable coefficients. Using Eq. (8), we fitted the extrudate bulk density data from the whole wheat flour and fish feed extrusion trials again. The average absolute deviations (AAD) of the fitting are $5.8 \%$ and $2.4 \%$ for the bulk densities of whole wheat and fish feed extrudate, respectively. The regression results for the fish feed extrusion trials are shown in Fig. 5. It can be seen that Eq. (8) gives better regression results for the experimental bulk density data.

\section{Conclusions and discussions}

In this work, we proposed a phenomenological model to correlate extrudate expansion and extrusion process parameters for a twin-screw extrusion process using dimensional analy-

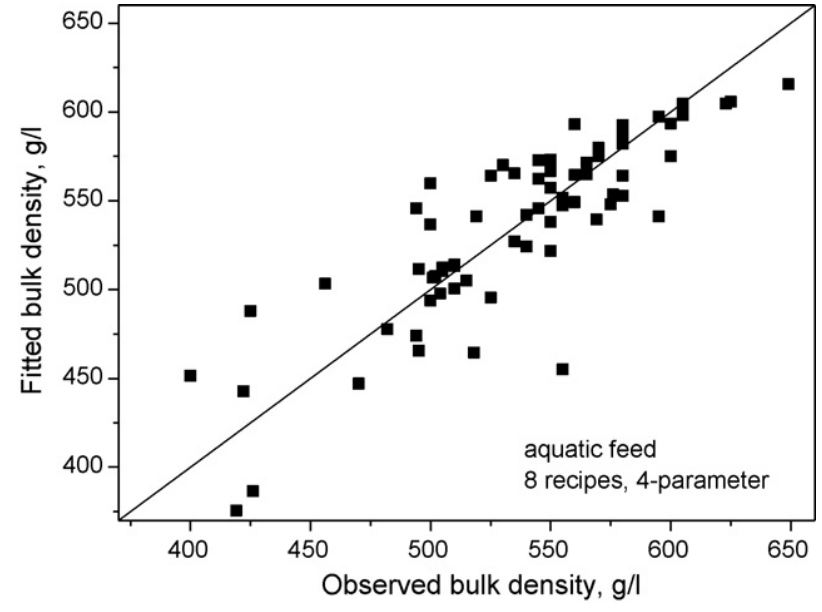

Fig. 5 - Observed and fitted value for the bulk density of fish feed extrudate with Eq. (8).

sis methodology. Through Buckingham dimensional analysis theory, three dimensionless groups were derived to form the model. The model satisfactorily correlates the experimental data for whole wheat flour and fish feed extrusions. A modified 4-parameter expansion model was also investigated in this work. It has been demonstrated that the proposed dimensionless equation gives an opportunity to correlate the experimental data in a consistent format, and opens a way to build a more comprehensive physical meaningful model for a food extrusion cooking process. The extrudate expansion model provides a tool for engineers to quantitatively observe the interactions between operational parameters and extrudate expansion in a food extrusion cooking process.

In engineering applications, it will be very useful and convenient if one equation can be employed to correlate the extrusion behaviours in different types of extruders. Because dimensional analysis theorem is independent of process equipment structure characteristics, it is very possible to use the proposed dimensionless equation to correlate the process parameters and product bulk density in different type of extruders. Therefore, the proposed equation should be evaluated in a single-screw extruder extrusion process.

In practice, the relationship between processing ingredient properties, process parameters and product bulk density are very important for extrusion process operation and control. The proposed equation in this work does not have the ingredient property term in its formula. Further investigation is needed to develop such kind of equation from the dimensional analysis methodology or other methods.

\section{Acknowledgments}

We acknowledge Professor Jens Adler-Nissen and Associate Professor Jørgen Risum from Denmark Technical University for many inspiring discussions, Hanne T. Rasmussen, Jørgen Busk from Danish Technological Institute for their contribution to the experimental work in pilot plant, Edgar Strobel from Coperion Werner\&Pfleiderer GmbH \& Co. KG, Stuttgart, Germany for supplying calculation equations for $\mathrm{W}$ \& P extruder properties and finally A.J. van der Goot from Wageningen University for his comments concerning pump efficiency. 


\section{References}

Altan, A., McCarthy, K.L. and Maskan, M., 2008, Evaluation of snack foods from barley-tomato pomace blends by extrusion processing. Journal of Food Engineering, 84(2): 231-242.

Alvarez-Martinez, L., Kondury, K.P. and Harper, J.M., 1988, A general model for expansion of extruded products. Journal of Food Science, 53(2): 609-615.

Barenblatt, H.A., (2003). Scalling. (Cambridge University Press, Cambridge, United Kingdom).

Bruin, S. and Jongen, T.R.G., 2003, Food process engineering: the last 25 years and challenges ahead. Comprehensive Reviews in Food Science and Food Safety, 2: 42-812.

Bruin, S., Zuilichem, D.J.v. and Stolp, W., 1978, A review of fundamental and engineering aspects of extrusion of biopolymers in a single screw extruder. Journal of Food Process Engineering, 1: 1-372.

Brümmer, T., Meuser, F., Van Lengerich, B. and Niemann, C., 2002, Expansion and functional properties of corn starch extrudates related to their molecular degradation, product temperature and water content. Starch/Staerke, 54(1): 9-15.

Buckingham, E., 1914, Similar systems and dimensional equations. Physical Review, 4: 345-376.

Cai, W. and Diosady, L.L., 1993, Modeling of expansion and water solubility index of wheat starch during extrusion cooking. Acta Alimentaria, 22(3): 181-192.

Ding, Q., Ainsworth, P., Plunkett, A., Tucker, G. and Marson, H., 2006, The effect of extrusion conditions on the functional and physical properties of wheat-based expanded snacks. Journal of Food Engineering, 73(2): 142-148.

Esbensen, K.H., Guyot, D. and Westad, F., (2000). Mutivariate Data Analysis: In Practice: An Introduction to Multivariate Data Analysis and Experimental Design (4th ed.). (CAMO ASA, Oslo, Norway), p. 600

Kokini, J.L., Chang, C.N. and Lai, L.S., 1992, The role of rheological properties on extrudate expansion, in Food Extrusion Science and Technology, Kokini, J.L., Ho, C.T., \& Karwe, M.V. (eds) (Marcel Dekker Inc, New York, NY), pp. 631-651. (Marcel Dekker Inc, New York, NY).

Kokini, J.L., Ho, C.T., \& Karwe, M.V. (eds) 1992, Food Extrusion Science and Technology. (Marcel Dekker, New York).

Lim, L.C., Sablani, S.S. and Mujumdar, A.S., 2007, Dimensional analysis, in Handbook of Food and Bioprocess Modeling Techniques, Sablani, S.S., Rahman, M.S., \& Datta, A.K., et al. (eds) (CRC Press, Boca Raton), pp. 533-561. (CRC Press, Boca Raton).

Montgomery, D.C., (2001). Design and Analysis of Experiments (5th ed.). (John Wiley \& Sons, Inc, New York), p. 456

Moraru, C.I. and Kokini, J.L., 2003, Nucleation and expansion during extrusion and microwave heating of cereal foods. Comprehensive Reviews in Food Science and Food Safety, 4: 120-1382.

Perry, R.H., \& Green, D.W. (eds) 1999, Perry's Chemical Engineers Handbook. (McGraw-Hill, New York)

Rayleigh., 1915, The principle of similitude. Nature, 95: 66-68.

Stahl, W.R., 1962, Similarity and dimensional method in biology. Science, 137: 205-212.

Tayeb, J., Valle, G.D., Barres, C. and Vergnes, B., 1992, Simulation of transport phenomena in twin-screw extruders, in Food Extrusion Science and Technology, Kokini, J.L., Ho, C.T., \& Karwe, M.V. (eds). (Marcel Dekker, Inc, New York), p. 41

Weast, R.C., \& Astle, M.J. (eds) 1981, CRC Handbook of Chemistry and Physics. (1st ed., pp. 306-323). (CRC Press, Boca Raton, Florida) (Chapter F) 